FAROS URBANOS, SANTIAGO, CHILE

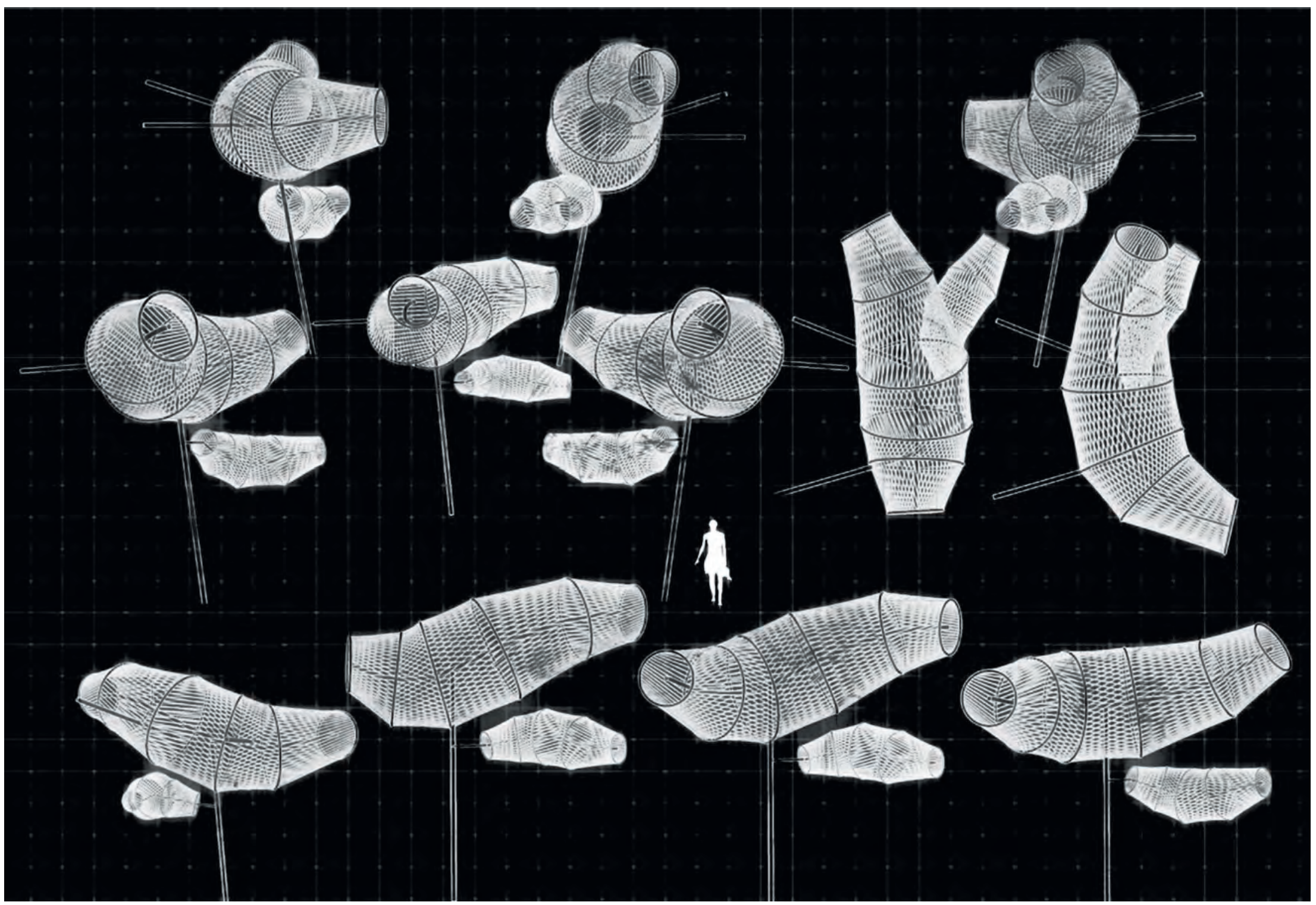

Verónica Arcos | Socia, Animales Arquitectos, Santiago

Arquitecta, Universidad Central de Chile, 2001. Máster en Arquitectura, Berlage Institute, 2004. Ha enseñado en las universidades Católica de Chile, Federico Santa María, de Talca, UNIACC, de Pensilvania, Internacional de Catalunya y en Elisava Escola de Dysenny. En 2006 fundó su propio estudio VAA, donde ha desarrollado una línea de investigación que especula sobre la relación entre patrones formales, su interacción y desempeño con el entorno y sus habitantes. Actualmente es socia de "Animales Arquitectos".

Jean Petitpas | Socio, Animales Arquitectos, Santiago

Arquitecto, Pontificia Universidad Católica de Valparaíso, 2005. Se inició como escultor en el Taller de José Balcells, en la Ciudad Abierta de Ritoque. Fue profesor ayudante de la Escuela de Arquitectura de la PucV hasta 2009; en 2010 se traslada a Santiago para iniciar colaboraciones con el estudio de Smiljan Radic y el de José Cruz Ovalle, del cual actualmente forma parte. A fines de 2011 funda "Animales Arquitectos". 

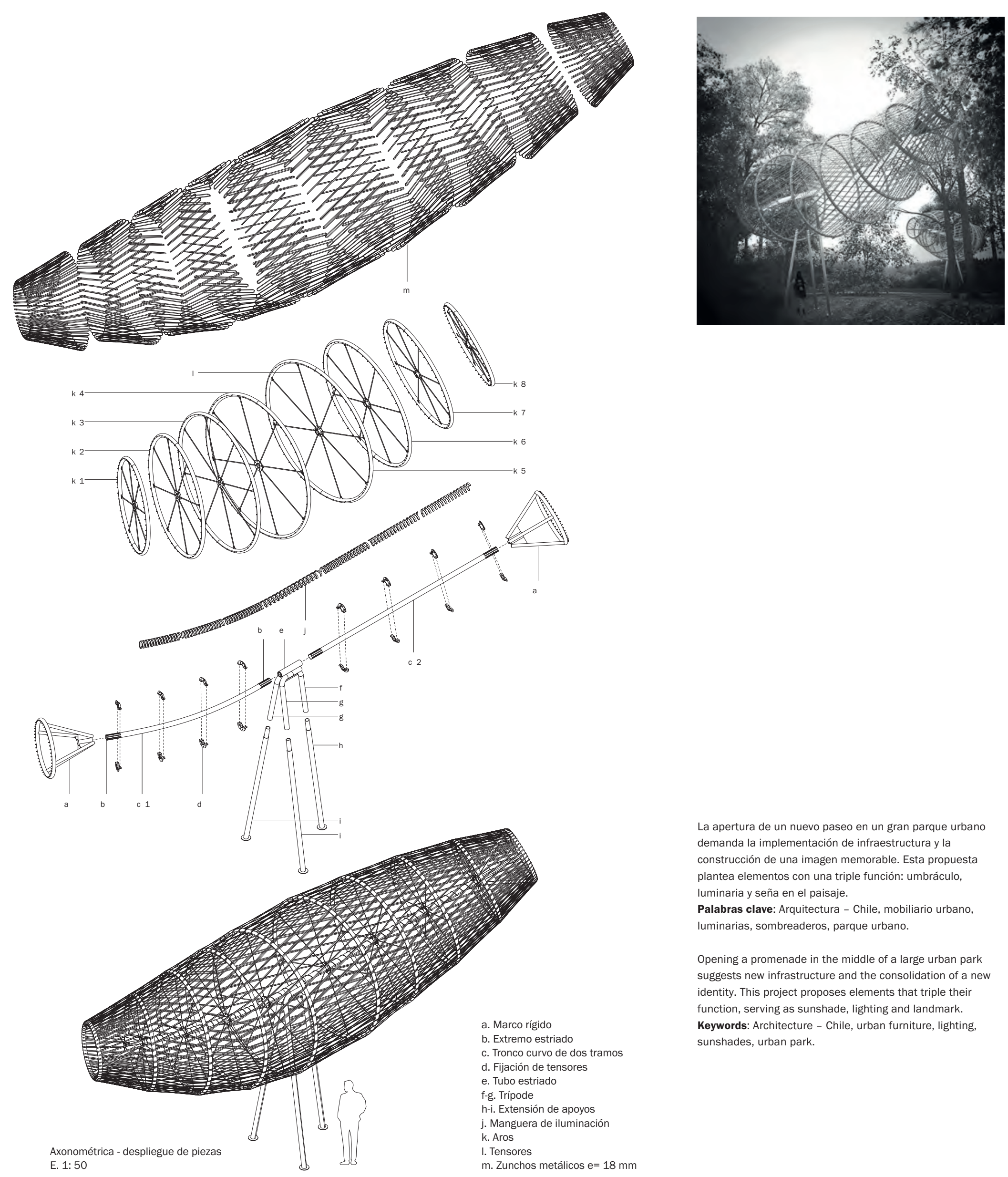

La apertura de un nuevo paseo en un gran parque urbano demanda la implementación de infraestructura y la construcción de una imagen memorable. Esta propuesta plantea elementos con una triple función: umbráculo, luminaria y seña en el paisaje.

Palabras clave: Arquitectura - Chile, mobiliario urbano, luminarias, sombreaderos, parque urbano.

Opening a promenade in the middle of a large urban park suggests new infrastructure and the consolidation of a new identity. This project proposes elements that triple their function, serving as sunshade, lighting and landmark. Keywords: Architecture - Chile, urban furniture, lighting, sunshades, urban park. 

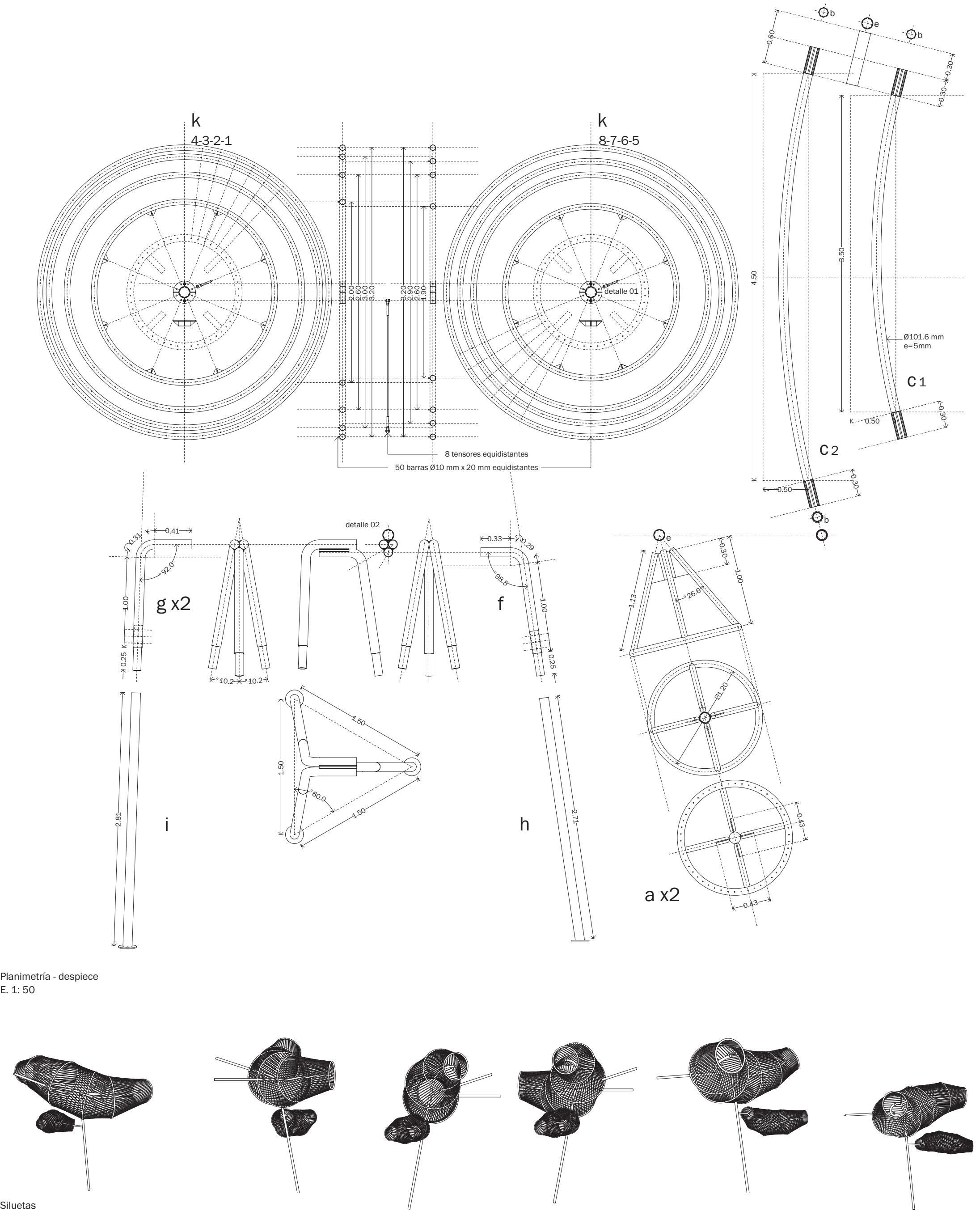


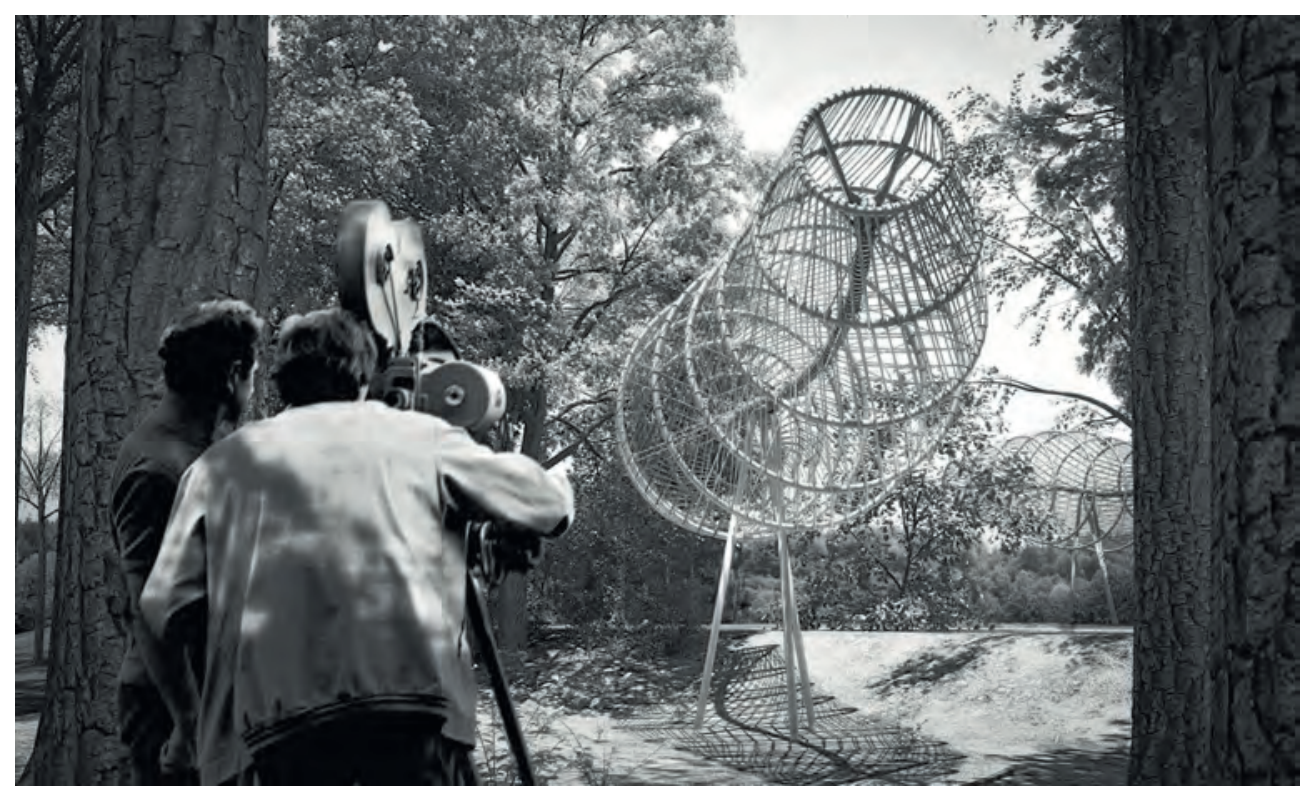

El proyecto propone un conjunto de elementos que, a la manera de los faros, pueda contribuir a definir y consolidar un nuevo borde en el Parque Metropolitano sobre el cerro San Cristóbal: se trata del camino del canal El Carmen, que corona al Parque Bicentenario de la Infancia y azocala la ladera norponiente. Estos nuevos objetos proveerán sombra de día y luz de noche: un conjunto de grandes lámparas que miradas desde la distancia conformarán una suerte de constelación.

La naturaleza del lugar donde están situados requiere una intervención que reflexione en cómo se habita el espacio periférico del cerro, particularmente de esa fracción. Vadeando al objetivo estrictamente funcional -instalación de pasamanos y basureros- se ha optado por generar un nuevo contenido temático, que revindique el aprecio de los usuarios por el lugar. La ladera, menos urbanizada y urgentemente llamada a constituirse en espacio público, posibilita un tratamiento mediante el cual se aborde la extensión natural sin someterla.

El conjunto de "faros" se alza como un achurado en levitación, que recrea el espesor y la posición de la vegetación sobre la superficie más árida del cerro. Su diseño permite variaciones tanto en su configuración geométrica y posición espacial como en su levedad materialidad. Se ha establecido un orden de fundas tejidas con zunchos metálicos que pierden definición a medida en que el paseante se acerca a ellas para, en la proximidad, traspasar en forma de sombra su densidad al suelo. Al ocaso y esta vez por dentro, la misma funda recoge la luz emitida desde el tronco de la estructura.

Este proyecto se enmarca en la producción del Laboratorio de Arte y Arquitectura dirigido por ANIMALES ARQUITECTOS en colaboración con la Fundación Sendero de Chile, cuya sede se emplaza en el Parque Metropolitano de Santiago. Las directrices generales del laboratorio se fundamentan en el uso del parque como un campo de ensayo, indagando sobre nuevos usos posibles del espacio y sobre la definición de infraestructuras que apunten a extender los alcances del patrimonio cultural del cerro. ARQ

\section{Bibliografía sugerida}

PALMER, Montserrat (ed.). Revista ARQ N ${ }^{\circ} 60$ - Arquitectura infraestructura. Ediciones ARQ, Santiago, 2005.

ARCos, Verónica. "Casa de Todos”. Revista ARQ № 75 - Casas. Ediciones ARQ, Santiago, 2011.
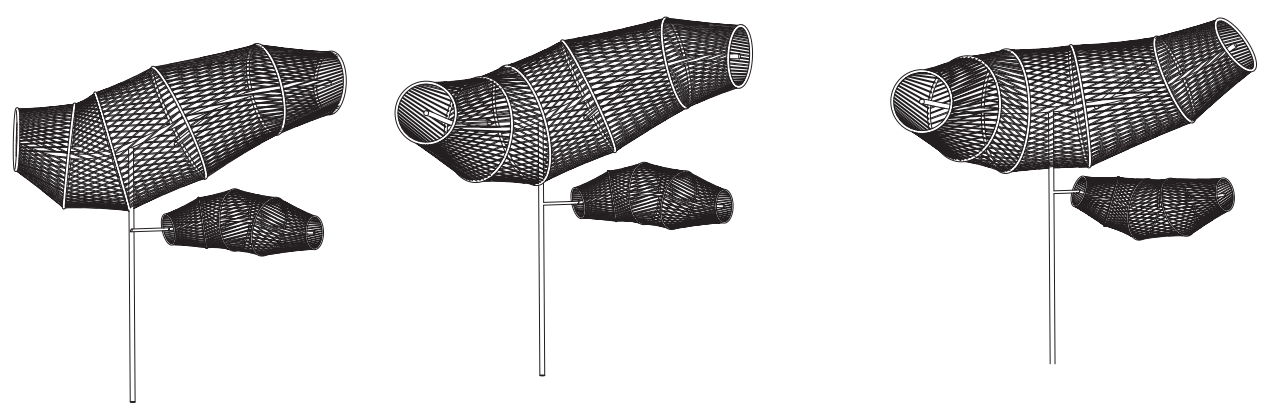

FARos URBANos | Arquitectos: Verónica Arcos, Jean Petitpas Animales Arquitectos | Arquitecto colaborador: Manuel Araya I Agradecimientos a: Amarí Peliowski, Manuel Pomar y Mar Oliver | Ubicación: Parque Metropolitano, Santiago, Chile | Cliente: Fundación Sendero de Chile | Cálculo estructural: José Manuel Morales | Materialidad: tenso estructura compuesta por perfiles de Fe y tensores; envolvente de zunchos metálicos | Presupuesto: US $\$ 528 / \mathrm{m}^{2}$; UF $11 / \mathrm{m}^{2}$ | Superficie de terreno: $1.400 \mathrm{~m}^{2}$ | Superficie construida: $140 \mathrm{~m}^{2}$ | Año de proyecto: 2012 | Imágenes: Animales arquitectos. 